\title{
Dipeptidyl peptidase-4 inhibitors and GLP-1 reduce myocardial infarct size in a glucose- dependent manner
}

Derek J Hausenloy ${ }^{1 \dagger}$, Hannah J Whittington ${ }^{1 \dagger}$, Abigail M Wynne', Shah S Begum', Louise Theodorou', Niels Riksen ${ }^{2}$, Mihaela M Mocanu ${ }^{1}$ and Derek M Yellon ${ }^{1^{*}}$

\begin{abstract}
Background: The dipeptidyl peptidase-4 (DPP-4) inhibitors Sitagliptin and Vildagliptin lower blood glucose by augmenting endogenous levels of glucagon-like peptide-1 (GLP-1), an incretin which also confers cardioprotection. As such, we hypothesized that treatment with DPP-4 inhibitors are also cardioprotective.

Methods: In ex vivo experiments: Male Sprague-Dawley rats were randomized to receive by oral gavage either Vildagliptin (20 mg/kg/day), Sitagliptin (100 mg/kg/day), or water for 2 weeks. Excised hearts were Langendorffperfused with buffer containing either $5 \mathrm{mmol} / \mathrm{L}$ or $11 \mathrm{mmol} / \mathrm{L}$ glucose and subjected to 35 minutes ischaemia/ 120 minutes reperfusion. In in vivo experiments: Male young Wistar and Sprague-Dawley rats, middle aged Wistar and Goto-Kakizaki diabetic rats were randomized to receive by oral gavage either Sitagliptin $(100 \mathrm{mg} / \mathrm{kg} /$ day $)$, or water for 2 weeks. Rats were then subjected to 30 minutes ischaemia/120 minutes reperfusion and infarct size ascertained.

Results: Two weeks pre-treatment with either Vildagliptin or Sitagliptin reduced ex vivo myocardial infarction (MI) size in hearts perfused with buffer containing $11 \mathrm{mmol} / \mathrm{L}$ glucose but not $5 \mathrm{mmol} / \mathrm{L}$ glucose. This effect was abolished by Exendin 9-39 (GLP-1 receptor antagonist) and H-89 (PKA antagonist). Treatment of perfused hearts with native GLP-1 was also glucose-sensitive, reducing MI size, at glucose concentrations 7, 9, and $11 \mathrm{mmol} / \mathrm{L}$ but not at $5 \mathrm{mmol} / \mathrm{L}$. Finally, Sitagliptin reduced in vivo $\mathrm{Ml}$ size in middle aged Wistar (7-8 mmol/L glucose) and GotoKakizaki (9-10 mmol/L glucose) rats where blood glucose was elevated, but not in young Wistar (5 mmol/L glucose) or Sprague-Dawley ( $5 \mathrm{mmol} / \mathrm{L}$ glucose) rats, where blood glucose was normal.
\end{abstract}

Conclusions: We find that chronic treatment with DPP-4 inhibitors reduced MI size, via the GLP-1 receptor-PKA pathway, in a glucose-dependent manner. Glucose-sensitive cardioprotection of endogenous GLP-1 in diabetic patients may in part explain why intensive control of serum glucose levels has been associated with increased cardiovascular risk.

Keywords: Ischaemia, Reperfusion, Glucagon-like peptide 1, Sitagliptin, Vildagliptin, Dipeptidyl peptidase-4 inhibitor, Blood glucose

\footnotetext{
*Correspondence: d.yellon@ucl.ac.uk

${ }^{\dagger}$ Equal contributors

${ }^{1}$ The Hatter Cardiovascular Institute, UCL Institute of Cardiovascular Science and NIHR University College London Hospitals Biomedical Research Centre, 67 Chenies Mews, London WC1E 6HX, UK

Full list of author information is available at the end of the article
} 


\section{Background}

Coronary heart disease (CHD) is the leading cause of death in diabetic patients. According to the World Health Organisation more than 220 million people worldwide have diabetes. Patients with diabetes are two to three times more likely to develop CHD, and experience worse clinical outcomes following an acute myocardial infarction [1-3], coronary angioplasty [4], and cardiac bypass surgery [5-7]. The reason for the worse cardiovascular outcomes in diabetic patients is currently unclear. Pre-clinical animal studies suggest that there may be specific defects in diabetic cardiomyocytes which may be responsible including increased mitochondrial generation of reactive oxygen species, impaired signalling via the PI3-Akt survival kinase pathway and reduced rates of ATP synthesis (reviewed in $[8,9])$. Clearly, novel cardioprotective strategies are required to improve clinical outcomes in diabetic patients with CHD.

In this respect, emerging evidence suggests that the incretin, glucagon-like peptide (GLP-1), GLP-1(7-36) amide and its breakdown product GLP-1(9-36)amide both have the ability to protect the heart against acute ischaemia-reperfusion injury (IRI) [10-12], as well as having direct beneficial effects on metabolism [13,14]. However, GLP-1 is rapidly broken down in the circulation by the enzyme, dipeptidyl peptidase-4 (DPP-4). The anti-diabetic agents, Sitagliptin and Vildagliptin both lower blood glucose by inhibiting DPP-4, which augments endogenous levels of GLP-1 [15]. Therefore, in this study we utilized both ex vivo and in vivo models of ischaemia reperfusion injury (IRI) to investigate whether chronic treatment with the DPP-4 inhibitors, Sitagliptin and Vildagliptin, also confer cardioprotection.

\section{Methods}

\section{Animals}

Animal experiments were conducted in strict accordance with the Animals (Scientific Procedures) Act 1986 published by the UK Home Office and the Guide for the Care and Use of Laboratory Animals published by the US National Institutes of Health (NIH Publication No. 85-23, revised 1996). Approval has been granted by the University College London ethics review board. All efforts were made to minimize suffering.

Male Sprague-Dawley (SD) rats (3-4 months) were used for the ex vivo isolated heart investigations. Male SD rats (3-4 months), Wistar rats (3-4 months), middle aged Wistar rats (7-8 months) and middle aged Goto Kakizaki (GK) rats (7-8 months) were used for the in vivo experiments. Animals received humane care in accordance with the United Kingdom Animal (Scientific Procedures) Act of 1986. Approval was granted by a university ethics review board. The study conforms with the Guide for the Care and Use of Laboratory Animals published by the US National Institutes of Health (NIH Publication No. 85-23, revised 1996). For oral gavage, Sitagliptin $(100 \mathrm{mg} / \mathrm{kg} /$ day $)$ and Vildagliptin $(20 \mathrm{mg} / \mathrm{kg} /$ day) were dissolved in water, concentrations sufficient to increase GLP-1 levels $[16,17]$. All other reagents were of standard analytical grade.

\section{Ex vivo isolated perfused rat heart model of acute myocardial infarction}

Rats were terminally anesthetised with sodium pentobarbital (55 mg/kg intraperitoneally) and heparin (300 IU). The hearts were rapidly excised into ice-cold buffer, and mounted on a constant pressure $(80 \mathrm{mmHg})$ Langendorffperfusion apparatus and perfused with modified KrebsHenseleit bicarbonate buffer in $\mathrm{mmol} / \mathrm{L}: \mathrm{NaCl} 118.5$, $\mathrm{NaHCO}_{3}$ 25.0, $\mathrm{KCl} 4.8, \mathrm{MgSO}_{4} 1.2, \mathrm{KH}_{2} \mathrm{PO}_{4} 1.2, \mathrm{CaCl}_{2}$ 1.7 and glucose 5.0 or 11.0. The buffer was gassed with $95 \% \mathrm{O}_{2} / 5 \% \mathrm{CO}_{2}$ and $\mathrm{pH}$ maintained at $7.35-7.45$ at $37.0^{\circ} \mathrm{C}$. A suture was placed around the left main coronary artery and the ends inserted into a pipette tip to form a snare. A latex, fluid-filled balloon was placed in the left ventricle through an incision in the left atrial appendage and inflated to a pressure of $8-10 \mathrm{mmHg}$. Left ventricular developed pressure, heart rate and coronary flow were monitored at regular intervals. Temperature was constantly measured via a thermo-probe inserted into the pulmonary artery and maintained between $37.0 \pm 0.2^{\circ} \mathrm{C}$. Regional myocardial ischaemia was induced by tightening the suture placed around the left anterior descending coronary artery (LAD) for $35 \mathrm{mi}-$ nutes and reperfusion for 120 minutes initiated by releasing the snare. At the end of the reperfusion period the suture was tied and the heart perfused with $0.25 \%$ Evans Blue in saline to delineate the area at risk. Hearts were frozen at $-20^{\circ} \mathrm{C}$ for several hours before infarct size determination.

\section{In vivo rat model of acute myocardial infarction}

Rats were anesthetised with sodium pentobarbital (20 mg/kg intraperitoneally) and heparin (300 IU). The rats were intubated and ventilated with a Harvard ventilator (room air, 70 strokes $/ \mathrm{min}$, tidal volume: $8-9 \mathrm{ml} / \mathrm{kg}$ ). Body temperature was maintained at $37.4 \pm 1^{\circ} \mathrm{C}$ by means of a rectal probe thermometer attached to a temperature control system (CMA450). A lateral thoracotomy was performed to expose the heart and a suture placed around the LAD. The suture was tightened using a loop system to create LAD ligation and regional ischaemia which was confirmed by a change in ECG profile. Following 30 minutes of ischaemia, the vessel was reperfused for 120 minutes. At the end of reperfusion, the heart was removed from the chest, the LAD permanently occluded and the heart perfused with $0.5 \%$ Evans blue in saline to delineate the area at risk. Hearts 
were frozen at $-20^{\circ} \mathrm{C}$ for several hours before infarct size determination.

\section{Myocardial Infarct size determination}

All hearts were sliced into $2 \mathrm{~mm}$ thick transverse sections and incubated in triphenyltetrazolium chloride solution (TTC; $1 \%$ in phosphate buffer). TTC reacts with intracellular dehydrogenases to stain viable risk zone tissue red leaving the infarcted areas off-white. The slices were then transferred and fixed in 10\% formalin overnight. All the slices from one heart were scanned into the computer for analysis or drawn onto acetate, and the area at risk, area of infarction, and area of viable risk zone was delineated and converted to a volume assuming a $2 \mathrm{~mm}$ slice thickness. Image J or computerised planimetry (Summa Sketch III, Summagraphics, Seymour, CT, USA) were then used to assess the percentage of infarcted tissue in the myocardium area at risk ( $\mathrm{I} / \mathrm{R} \%)$ [18].

\section{Blood glucose assessment}

Samples for fasting blood glucose were taken at baseline and after 2 weeks treatment with Sitagliptin, Vildagliptin or water control. Blood glucose measurements $(\mathrm{mmol} / \mathrm{L})$ were determined using an ABL 700 series blood gas analyzer (Radiometer, Copenhagen).

\section{Experimental protocols for isolated heart perfusion}

To investigate the effect of different glucose concentrations within the perfusion buffer, isolated rat hearts were perfused with $5 \mathrm{mmol} / \mathrm{L}$ versus $11 \mathrm{mmol} / \mathrm{L}$ glucose during control and ischaemic preconditioned (IPC) experiments (the latter used as a positive control). Hearts were perfused with buffer containing glucose at either $5 \mathrm{mmol} / \mathrm{L}$ or $11 \mathrm{mmol} / \mathrm{L}$ and subjected to stabilization, ischaemia and reperfusion or to a standard IPC protocol (2 cycles of 5 minutes global ischaemia and 10 minutes reperfusion) prior to ischaemia and reperfusion.

Animals were randomly assigned to receive, Sitagliptin (100 mg/kg/day), Vildagliptin $(20 \mathrm{mg} / \mathrm{kg} /$ day $)$ or water alone given daily by oral gavage for 2 weeks. Hearts were then excised from animals and mounted on the Langendorff-apparatus, and randomized to receive one of the experimental protocols summarized in Figures 1A and 1B. To examine the role of GLP-1 and PKA in the setting of the anti-diabetic gliptin drugs, Exendin 9-39 or DMSO (3 nM, a GLP-1 receptor antagonist, Sigma) were added into the perfusate in selected experiments and $\mathrm{H}-89$ or DMSO ( $5 \mu \mathrm{M}$, a PKA antagonist, Sigma) was administered by intraperitoneal (I.P) injection prior to excision of the heart.

To investigate the cardioprotective effects of GLP-1 (0.3 nM, Novo Nordisk, Denmark) at different concentrations of glucose; hearts were rapidly excised from untreated rats and mounted on the Langendorff-apparatus.
The perfusion buffer contained 5, 7, 9 or $11 \mathrm{mmol} / \mathrm{L}$ of glucose; and either DMSO vehicle $(0.01 \%)$ or GLP-1 $(0.3 \mathrm{nM})$ throughout the entire protocol.

\section{Experimental protocols for in vivo investigations}

To investigate whether the cardioprotective effect of DPP-4 inhibition were glucose sensitive in the in vivo setting; rats with differing blood glucose levels were treated by oral gavage with either Sitagliptin $(100 \mathrm{mg} /$ $\mathrm{kg} /$ day) or water for 2 weeks prior to LAD occlusion/reperfusion. Four groups were assessed SD, Wistar, middle aged Wistar and middle aged GK rats.

\section{Statistical analysis}

All values are expressed as mean \pm SEM. Myocardial infarct size was analyzed by one-way ANOVA and Fisher's protected least significant difference test for multiple comparisons. Differences were considered significant when $\mathrm{P}<0.05$.

\section{Results}

Both Sitagliptin and Vildagliptin pre-treatment reduced myocardial infarct size ex vivo in a glucose-dependent manner

There was no difference in the area at risk or haemodynamic variables between the treatment groups. The blood glucose levels after 2 week of treatment averaged $5.5 \pm 0.3 \mathrm{mmol} / \mathrm{L}, 5.7 \pm 0.2 \mathrm{mmol} / \mathrm{L}$ and $5.7 \pm 0.4 \mathrm{mmol} / \mathrm{L}$ for Sitagliptin, Vildagliptin and control, respectively.

Sitagliptin pre-treatment was found to reduce myocardial infarct size in hearts perfused with buffer containing $11 \mathrm{mmol} / \mathrm{L}$ of glucose $(30.7 \pm 3.4 \%$ with Sitagliptin versus $57.9 \pm 5.0 \%$ with control: $\mathrm{P}<0.05: \mathrm{N} \geq 6$ /group) but not $5 \mathrm{mmol} / \mathrm{L}$ glucose $(51.4 \pm 7.6 \%$ with Sitagliptin versus $53.1 \pm 5.4 \%$ with control: $\mathrm{P}>0.05: \mathrm{N} \geq 6$ /group) (Figure $2 \mathrm{~A}$ ). Similarly, Vildagliptin pre-treatment reduced myocardial infarct size in hearts perfused with buffer containing $11 \mathrm{mmol} / \mathrm{L}$ of glucose $(34.4 \pm 4.1 \%$ with Vildagliptin versus $52.9 \pm 5.2 \%$ with control: $\mathrm{P}<0.05: \mathrm{N} \geq 6$ /group) but not $5 \mathrm{mmol} / \mathrm{L}$ glucose $(53.2 \pm 4.8 \%$ with Vildagliptin versus $52.6 \pm 7.2 \%$ with control: $\mathrm{P}>0.05: \mathrm{N} \geq 6$ /group) (Figure 2B). Interestingly, ischaemic preconditioning (IPC) (used as a positive control in this setting) reduced myocardial infarct size in perfused rat hearts at both $5 \mathrm{mmol} / \mathrm{L}$ glucose $(18.8 \pm 2.7 \%$ with $\mathrm{IPC}$ versus $38.8 \pm$ $4.3 \%$ with control: $\mathrm{P}<0.05: \mathrm{N}>6 /$ group) and $11 \mathrm{mmol} / \mathrm{L}$ glucose $(21.7 \pm 4.8 \%$ with IPC versus $41.6 \pm 3.9 \%$ with control: $\mathrm{P}<0.05: \mathrm{N} \geq 6$ /group) (Figure $2 \mathrm{C}$ ).

Pharmacological inhibition of the GLP-1 receptor and the PKA signalling pathway abrogated both Sitagliptin and Vildagliptin-induced cardioprotection

There was no difference in the area at risk or haemodynamic variables between the treatment groups. The 

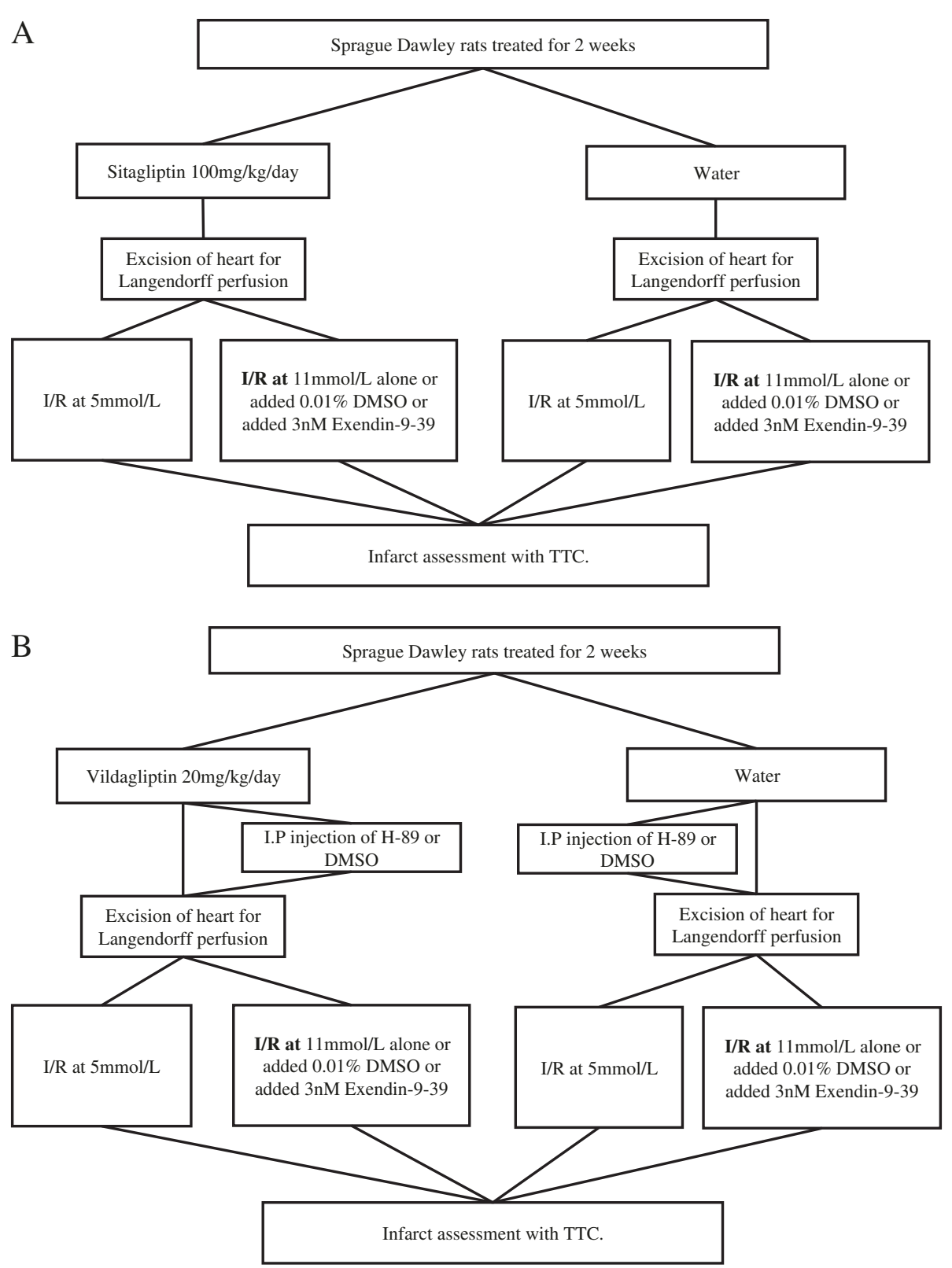

Figure 1 Ex-vivo experimental schedule for Sitagliptin and Vildagliptin pre-treatment. (A) Sprague-Dawley rats were treated for 2 weeks Sitagliptin (100 mg/kg/day) or water. (B) Sprague-Dawley rats were treated for 2 weeks Vildagliptin $(20 \mathrm{mg} / \mathrm{kg} / \mathrm{day})$ or water. All hearts were subjected to 35 minutes ischaemia followed by 120 minutes reperfusion (I/R).

infarct-limiting effects of Sitaglipitin at $11 \mathrm{mmol} / \mathrm{L}$ glucose were abolished by Exendin 9-39 (a GLP-1 receptor antagonist) $(63.6 \pm 5.5 \%$ with Sitagliptin + Exendin 9-39 versus $61.4 \pm 3.0 \%$ with Control + Exendin 9-39: $\mathrm{P}>0.05: \mathrm{N}>7$ /group)(Figure $2 \mathrm{~A}$ ) and the cardioprotective effects of Vildagliptin were abolished in the presence of Exendin 9-39 and H-89 (a PKA inhibitor) (61.5 \pm $3.3 \%$ with Vildagliptin + Exendin 9-39 and 59.4 $\pm 2.1 \%$ with Vildagliptin $+\mathrm{H}-89$ versus $35.0 \pm 5.0 \%$ with Vildagliptin + vehicle: $\mathrm{P}<0.05: \mathrm{N} \geq 6$ /group)(Figure 3 ). Importantly, the pharmacological inhibitors themselves did not influence infarct size significantly $(61.4 \pm 3.0 \%$ with control + Exendin 9-39 and 53.0 $\pm 4.9 \%$ with control + $\mathrm{H}-89$ versus $53.1 \pm 3.1 \%$ with control + vehicle: $\mathrm{P}>0.05$ : $\mathrm{N} \geq 6$ /group) (Figure 3).

\section{The infarct-limiting effects of GLP-1 treatment are also glucose-sensitive}

There was no difference in the area at risk or haemodynamic variables between the treatment groups. The perfusion of hearts with buffer containing GLP-1 reduced MI size, at glucose concentrations 7,9 , and $11 \mathrm{mmol} / \mathrm{L}$ but 


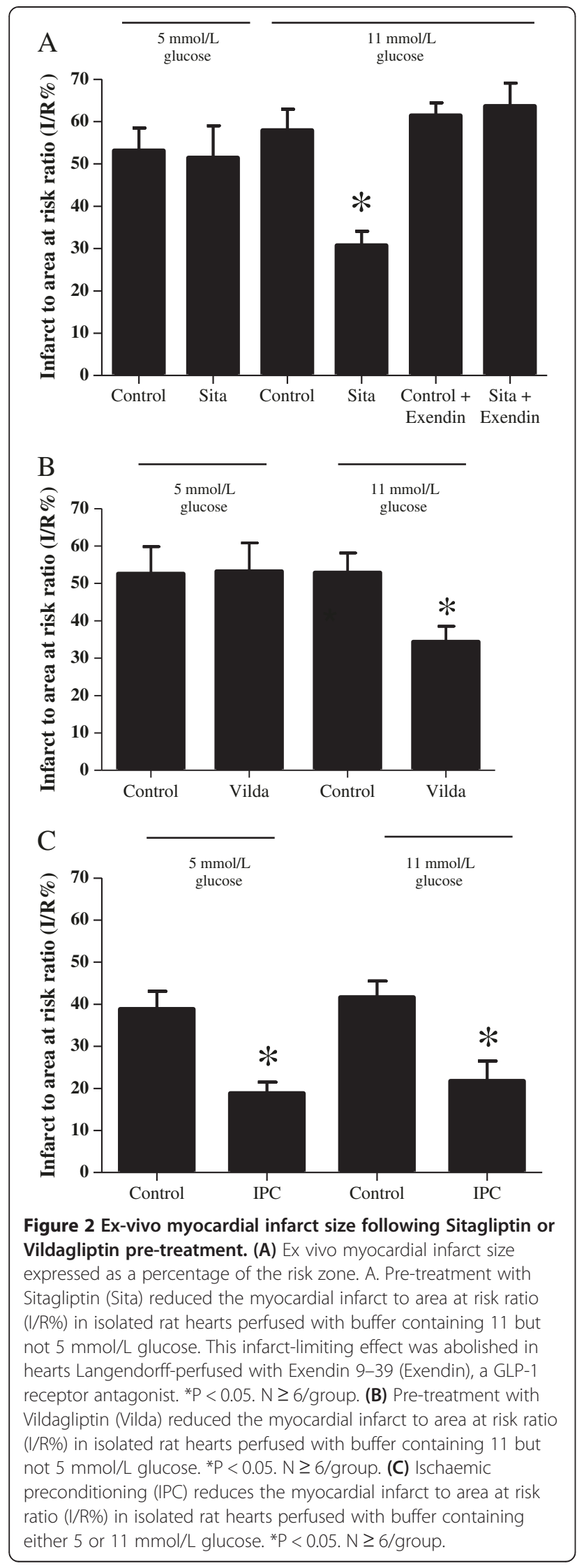

not at $5 \mathrm{mmol} / \mathrm{L}(30.8 \pm 0.6 \%$ at $7 \mathrm{mmol}, 29.3 \pm 0.6 \%$ at $9 \mathrm{mmol} / \mathrm{L}, 39.1 \pm 2.5 \%$ at $11 \mathrm{mmol} /$ Lpretreatment did not reduce blood glucose levels in any of the groups. versus $55.6 \pm 1.2 \%$ at $5 \mathrm{mmol} / \mathrm{L}: \mathrm{P}<0.05: \mathrm{N} \geq 6 /$ group) (Figure $4 \mathrm{~A}$ ). There was no difference in MI size in control hearts perfused at the different glucose concentrations $(57.1 \pm 0.7 \%$ at $5 \mathrm{mmol} / \mathrm{L}, 52.7 \pm 1.2 \%$ at $7 \mathrm{mmol} / \mathrm{L}, 55.6 \pm 1.5 \%$ at $9 \mathrm{mmol} / \mathrm{L}, 50.1 \pm 2.9 \%$ at $11 \mathrm{mmol} / \mathrm{L}: \mathrm{P}>0.05: \mathrm{N} \geq 6$ /group) (Figure 4B).

\section{Sitagliptin pre-treatment reduced myocardial infarct size in vivo in a glucose-dependent manner}

Blood glucose levels were not significantly different between SD and Wistar rats, but were significantly different between these groups and middle aged Wistar and GK rats (in $\mathrm{mmol} / \mathrm{L}: 5.5 \pm 0.3,5.6 \pm 0.2,7.5 \pm 0.3$ and $9.3 \pm 1.5$, respectively. $\mathrm{P}<0.05: \mathrm{N} \geq 6$ /group). Sitagliptin pre-treatment did not reduce blood glucose levels in any of the groups.

In the in vivo LAD occlusion/reperfusion studies, Sitagliptin pre-treatment was found to reduce myocardial infarct size in both middle aged Wistar and GK rats $(15.4 \pm 2.4 \%$ with Sitagliptin versus $44.8 \pm 4.0 \%$ with control in Wistars; and $29.10 \pm 5.3 \%$ with Sitagliptin versus $60.9 \pm 5.5 \%$ with control in GKs. $\mathrm{P}<0.05: \mathrm{N} \geq 6$ / group). However, in the SD or Wistar groups there were no differences in MI size $(42.1 \pm 7.4 \%$ and $34.5 \pm$ $5.9 \%$ with Sitagliptin versus $46.6 \pm 5.7 \%$ and $33.8 \pm 3.1 \%$ with control, respectively for SD and Wistar) (Figure 5 $\mathrm{A}, \mathrm{B})$.

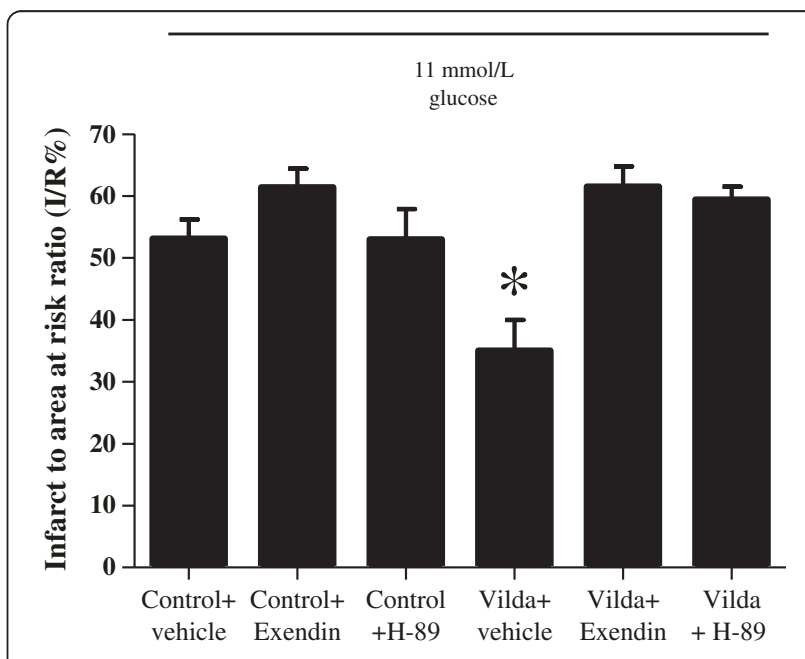

Figure 3 Ex vivo myocardial infarct size expressed as a percentage of the risk zone. The reduction in myocardial infarct to area at risk ratio (I/R\%) induced by pre-treatment with Vildagliptin (Vilda) was abolished by treatment with either Exendin 9-39 (Exendin), a GLP-1 receptor antagonist, or H-89 (a PKA antagonist). ${ }^{*} P<0.05 . N \geq 6$ /group. 


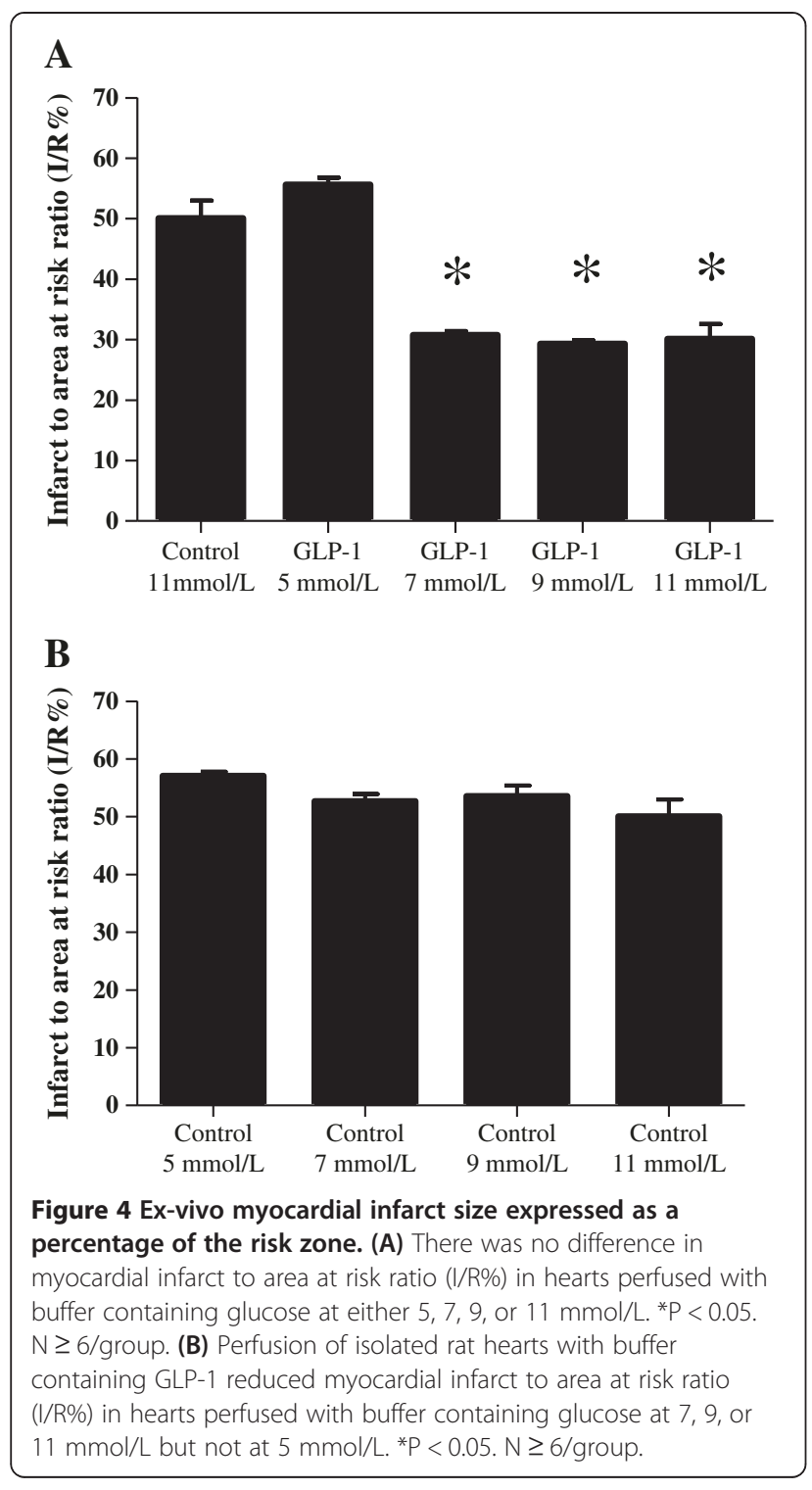

\section{Discussion}

The main findings from the present study are as follows: (a) We report that chronic oral treatment with the DPP-4 inhibitors, Sitagliptin or Vildagliptin, is cardioprotective as evidenced by a significant reduction in myocardial infarct size in the isolated perfused rat heart; (b) Interestingly, we show that for the first time, the infarct-limiting effects of Sitagliptin and Vildagliptin pre-treatment are sensitive to the glucose levels present during the myocardial infarction, such that cardioprotection was only observed in hearts infarcted in the presence of a high glucose of $11 \mathrm{mmol} / \mathrm{L}$, with loss of cardioprotection at lower glucose levels of $5 \mathrm{mmol} / \mathrm{L}$; (c) The infarct-limiting effects of DPP4 inhibitors were abrogated by pharmacological inhibitors of the GLP-1 receptor and the PKA signalling pathway; (d) The cardioprotection elicited by GLP-1 treatment was

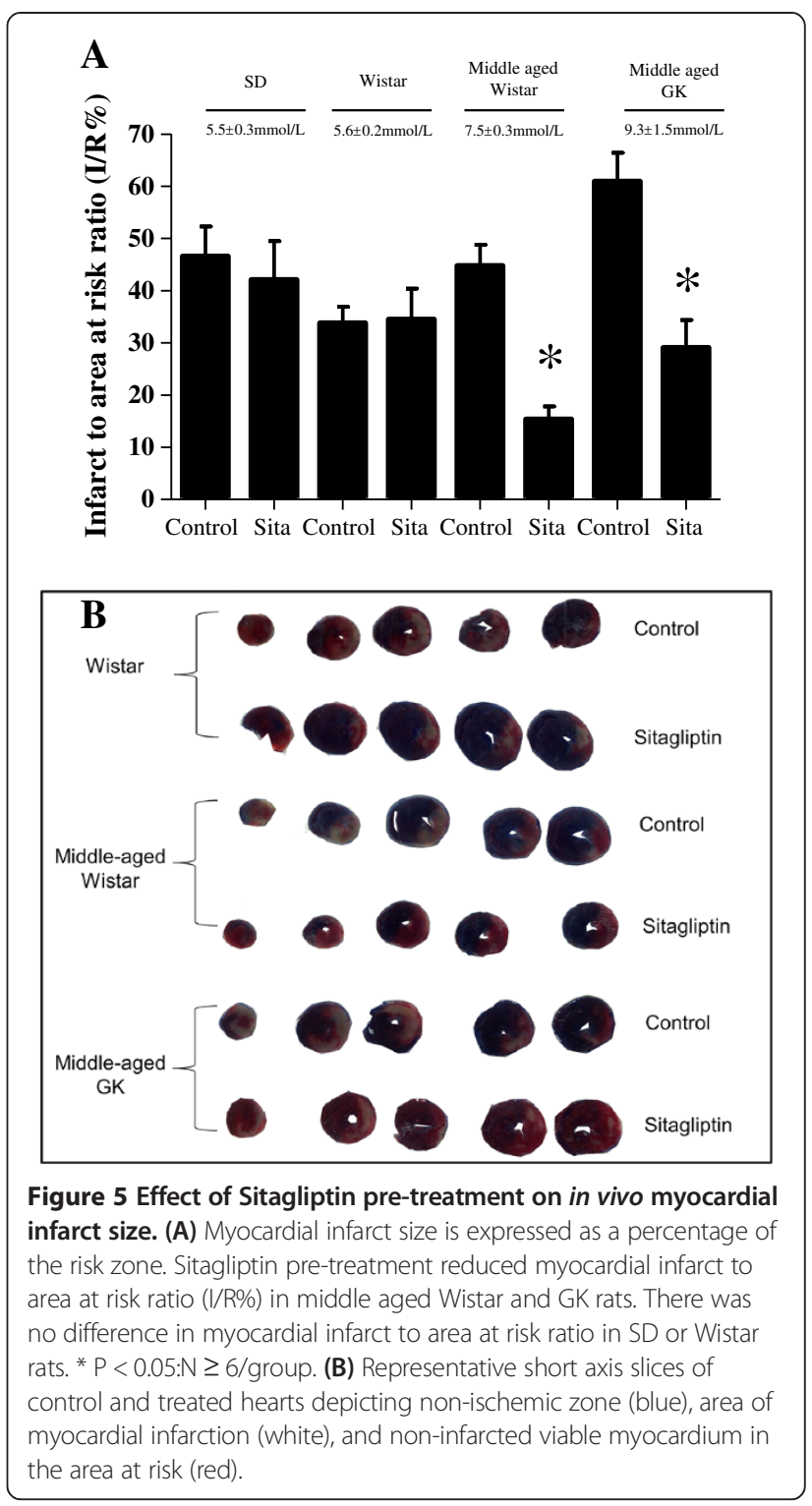

also glucose-sensitive with infarct limitation observed at glucose levels of 7, 9 and $11 \mathrm{mmol} / \mathrm{L}$ but not at $5 \mathrm{mmol} / \mathrm{L}$; (e) Sitagliptin related cardioprotection is also dependent on circulating glucose levels in the in vivo setting.

\section{GLP-1 cardioprotection}

Previous experimental studies have demonstrated that exogenous GLP-1 is cardioprotective. These cardioprotective effects were attributed to GLP-1 receptor activation and subsequent recruitment of numerous intracellular signalling pathways involving Akt, Erk1/2, p70S6K, and AMPK as well as the downstream phosphorylation and inhibition of the pro-apoptotic protein BAD (reviewed in [10]). In the current study we were keen to investigate whether endogenous GLP-1 levels, which are augmented by DPP-4 inhibitor therapy, also confer cardioprotection. Whilst 
conducting the current studies, Ye and co-workers [19] reported infarct-limitation with chronic Sitagliptin therapy through the activation of PKA. Interestingly, in that particular study the average blood glucose was about $7.5 \mathrm{mmol} / \mathrm{L}$, which corresponds to the levels of glucose in which we observed cardioprotection in our study. GLP-1 has also been suggested to improve myocardial contractility. GLP-1 enhanced cardiac voltage-gated L-type $\mathrm{Ca}^{2+}$ currents $\left.\mathrm{I}_{\mathrm{Ca}}\right)$ in canine ventricular cardiomyocytes. Interestingly, this augmentation was linked to the activation of cAMP-dependent PKA [20].

In contrast, Sauve and co-workers [21] failed to demonstrate myocardial infarct limitation with either genetic or pharmacological inhibition of DPP-4 using DPP-4 knockout mice and Sitagliptin, respectively, even though the blood glucose level was at $10 \mathrm{mmol} / \mathrm{L}$. Finally, it was also demonstrated that pre-treatment with Vildagliptin did not reduce MI size or prevent adverse LV remodelling in rats subjected to MI [22]. However, it is worth noting that in all these studies, these results were obained following permanent LAD ligation, and not a reperfusion MI model and in fact in two of these studies, DPP-4 inhibition exhibited improved survival rates. Interestingly, Zhao et al. [23] also demonstrated that exogenous GLP-1 was able to improve the recovery of left ventricular function in isolated Langendorff-perfused rat hearts subjected to acute IRI at $5 \mathrm{mM}$ glucose. However, in contrast to our study, the low-flow global myocardial ischaemia model was used making a direct comparison of results difficult.

\section{Other effects of DPP-4 inhibition}

Of note, an earlier experimental study attributed the cardioprotective effects of DPP-4 inhibition to the augmentation of endogenous stromal derived factor-1 (SDF-1), a known chemokine substrate of DPP-4 [24]. This latter study illustrates the non-specificity of DPP-4 inhibition for GLP-1, as it has a number of substrates including other gastrointestinal hormones, neuropeptides, cytokines, and chemokines [25]. In this regard, it was important for us to demonstrate that the DPP-4 inhibitor induced infarctlimitation in the isolated heart was blocked by GLP-1 receptor and PKA antagonists, suggesting the involvement of the myocardial GLP-1 receptor and subsequent activation of PKA. Furthermore, the observed glucose- sensitivity was also reproduced in vivo in animal models and with GLP-1, providing confirmatory evidence of the mediatory role of endogenous GLP-1 in DPP-4 inhibitor cardioprotection.

\section{Glucose-dependent cardioprotection}

Of interest, our study is the first to report infarct limitation with chronic Sitagliptin and Vildagliptin therapy being glucose-dependent, such that infarct-limitation was observed at a glucose level of $11 \mathrm{mmol} / \mathrm{L}$ and not at $5 \mathrm{mmol} / \mathrm{L}$. Interestingly, the glucose-dependency was also observed in GLP-1 mediated cardioprotection with infarct-limitation being observed at glucose levels of 7 , 9 , and $11 \mathrm{mmol} / \mathrm{L}$ but not at $5 \mathrm{mmol} / \mathrm{L}$. Moreover, the finding that Sitagliptin pre-treatment in middle aged Wistar and GK diabetic rats, both with hyperglycaemic blood glucose levels, limited infarct size but these effects were lost in normoglycaemic SD and Wistar rats, strengthens the idea that glucose-dependent cardioprotection with these agents is in fact an interesting phenomenon. It was important for us to demonstrate that the positive control for cardioprotection, ischaemic preconditioning, was still effective in hearts perfused with either 5 or $11 \mathrm{mmol} / \mathrm{L}$, demonstrating that infarctlimitation was possible at the lower blood glucose level in our model. The reason for the glucose-dependency of the cardioprotection elicited by both DPP-4 inhibitors and GLP-1 is not known and further studies are clearly required to investigate the mechanism underlying this observation.

Interestingly, it has been suggested that GLP-1 does not lower blood glucose at levels lower than $5 \mathrm{mM}$ and therefore the risk of hypoglycemia is significantly reduced. Previous experimental studies have reported glucosedependent changes in intracellular calcium and GLP-1 receptor-PKA signalling favouring high blood glucose levels [26]. Alternatively, the GLP-1 receptor could be differentially regulated in response to circulating blood glucose levels. In the presence of high glucose, GLP-1 could possibly activate G-protein coupled receptor signalling via its $G_{i}$ signalling pathway involving the Akt component of the RISK pathway leading to cardioprotection [27,28], whereas in conditions of low blood glucose this cardioprotective pathway is not favoured. Chai et al. [29] have recently showed that the administration of GLP-1 increased Akt-phosphorylation in cultured cells. However, the link between GLP-1, high glucose and Akt phosphorylation is yet to be fully investigated. Recent evidence has implicated AMPK as a mediator of GLP-1 cardioprotection [30], and low glucose levels have been shown to activate AMPK [31,32], and so the modulation of AMPK may explain in part the glucose-sensitivity of GLP-1 cardioprotection.

\section{Study limitations}

There are several limitations to the current experimental study: (1) Because we only reperfused the hearts for 2 hours in our in vivo model of acute IRI, we do not know if the cardioprotective effect elicited by the DPP-4 inhibitors had a long-term infarct-limiting effect: (2) The findings presented here concerning the glucose-sensitivity of GLP-1 cardioprotection are purely descriptive. Clearly further studies are required to elucidate the potential mechanisms underlying the glucose-sensitivity; (3) We only investigated 
the effect of H-89 (a PKA inhibitor) on Vildagliptininduced cardioprotection and ideally we should have also shown that H-89 blocked Sitagliptin mediated cardioprotection; (4) We did not measure serum levels of GLP-1.

\section{Clinical implications}

Although, proof-of-concept clinical studies have demonstrated cardioprotective benefit with exogenous GLP-1 therapy in the clinical settings of acute myocardial infarction [33], coronary artery bypass graft surgery [34] and heart failure [35], this treatment regimen requires a chronic subcutaneous infusion of GLP-1 given that the GLP-1 is rapidly broken down in the body by the enzyme DPP-4. Therefore, the findings of the current study suggest that augmenting endogenous levels of GLP-1 using clinically available DPP-4 inhibitors such as Sitagliptin and Vildagliptin may provide for a therapeutic strategy, which not only treats the diabetes but also protects the heart from ischaemia-reperfusion injury, the major cardiac complication of diabetes. An alternative strategy to DPP-4 inhibition would be to administer clinically available GLP-1 analogues such as Liraglutide [36] and Exenatide $[37,38]$ which are resistant to DPP-4 and are also cardioprotective in animal studies. Clinical studies are already underway investigating both GLP-1 analogues (Pharmacological Postconditioning to Reduce Infarct Size Following Primary PCI [POSTCON II]: ClinicalTrials.gov Identifier NCT00835848 and Effect of Additional Treatment With EXenatide in Patients With an Acute Myocardial Infarction (the EXAMI Trial: ClinicalTrials.gov Identifier NCT01254123) and DPP-4 inhibitors $[39,40]$ as therapy for cardiovascular disease. Lonborg et al. [41] has shown that the GLP-1 analogue, Exenatide, could reduce MI size when administered prior to PPCI in non-diabetic STEMI patients when compared to control. In that particular study the blood glucose ranged from $5-8 \mathrm{mmol} / \mathrm{L}$. It would be interesting to know whether the cardioprotective effect of Exenatide was affected by the presenting blood glucose levels.

\section{Conclusions}

Our present study confirms that DPP-4 inhibitors elicit cardioprotection against acute IRI similar to that seen for GLP-1, moreover these effects appear to be glucosesensitive.

\section{Abbreviations}

DPP-4: Dipeptidyl peptidase-4; GLP-1: Glucagon-like peptide-1; MI: Myocardial infarction; CHD: Coronary heart disease; IRI: Ischaemia reperfusion injury; SD: Sprague-Dawley; GK: Goto Kakizaki; LAD: Left anterior descending coronary artery; TTC: Triphenyltetrazolium chloride; I/R\%: Percentage of infarcted tissue in the myocardium area at risk; IPC: Ischaemic preconditioning; SDF-1: Stromal derived factor-1; PKA: Protein kinase A.

\section{Competing interests}

The authors declare that they have no competing interests.

\section{Authors' contributions}

DMY, DJH, MMM, RDC conceived the studies, wrote, reviewed and edited manuscript. HJW, AMW, SSB, LT, NR performed experiments, wrote, reviewed and edited manuscript. All authors read and approved the final manuscript.

\section{Acknowledgements}

This work was supported by the British Heart Foundation program grant number RG/03/007 and supported by researchers at the National Institute for Health Research University College London Hospitals Biomedical Research Centres funding scheme of which Professor Yellon is a senior investigator. In addition this work was also supported by research grants from MSD and Novartis. DH is supported by British Heart Foundation Senior Clinical Research Fellowship FS/10/039/28270.

The authors thank Louise Casson and other staff at the central unit of Biological Services Unit, UCL, London for the help in maintaining the animal colonies, administrating the drug and blood testing.

\section{Author details}

${ }^{1}$ The Hatter Cardiovascular Institute, UCL Institute of Cardiovascular Science and NIHR University College London Hospitals Biomedical Research Centre, 67 Chenies Mews, London WC1E 6HX, UK. ²Department of General Internal Medicine, Radboud University Nijmegen Medical Centre, Nijmegen, the Netherlands.

Received: 10 October 2013 Accepted: 11 October 2013

Published: 22 October 2013

\section{References}

1. Haffner SM, Lehto S, Ronnemaa T, Pyorala K, Laakso M: Mortality from coronary heart disease in subjects with type 2 diabetes and in nondiabetic subjects with and without prior myocardial infarction. N Engl J Med 1998, 339(4):229-234.

2. Malmberg $\mathrm{K}$, Yusuf $\mathrm{S}$, Gerstein $\mathrm{HC}$, et al: Impact of diabetes on long-term prognosis in patients with unstable angina and non-Q-wave myocardial infarction: results of the OASIS (Organization to Assess Strategies for Ischaemic Syndromes) registry. Circulation 2000, 102(9):1014-1019.

3. McGuire DK, Emanuelsson H, Granger CB, et al: Influence of diabetes mellitus on clinical outcomes across the spectrum of acute coronary syndromes. Findings from the GUSTO-Ilb study. GUSTO Ilb investigators. Eur Heart J 2000, 21(21):1750-1758.

4. Mathew V, Gersh BJ, Williams BA, et al: Outcomes in patients with diabetes mellitus undergoing percutaneous coronary intervention in the current era: a report from the prevention of REStenosis with tranilast and its outcomes (PRESTO) trial. Circulation 2004, 109(4):476-480.

5. Thourani VH, Weintraub WS, Stein B, et al: Influence of diabetes mellitus on early and late outcome after coronary artery bypass grafting. Ann Thorac Surg 1999, 67(4):1045-1052.

6. Calafiore AM, Di Mauro M, Di Giammarco G, et al: Effect of diabetes on early and late survival after isolated first coronary bypass surgery in multivessel disease. J Thorac Cardiovasc Surg 2003, 125(1):144-154.

7. Alserius T, Hammar N, Nordqvist T, Ivert T: Risk of death or acute myocardial infarction 10 years after coronary artery bypass surgery in relation to type of diabetes. Am Heart J 2006, 152(3):599-605.

8. Huisamen B: Protein kinase B in the diabetic heart. Mol Cell Biochem 2003, 249(1-2):31-38.

9. Rolo AP, Palmeira CM: Diabetes and mitochondrial function: role of hyperglycemia and oxidative stress. Toxicol Appl Pharmacol 2006, 212(2):167-178

10. Hausenloy DJ, Yellon DM: GLP-1 therapy: beyond glucose control. Circ Heart Fail 2008, 1:147-149.

11. Bose AK, Mocanu MM, Carr RD, Brand CL, Yellon DM: Glucagon-like peptide 1 can directly protect the heart against ischemia/reperfusion injury. Diabetes 2005, 54(1):146-151.

12. Bose AK, Mocanu MM, Carr RD, Yellon DM: Myocardial ischaemiareperfusion injury is attenuated by intact glucagon like peptide- 1 (GLP-1) in the in vitro rat heart and may involve the p70s6K pathway. Cardiovasc Drugs Ther 2007, 21(4):253-256 
13. Nikolaidis LA, Elahi D, Shen YT, Shannon RP: Active metabolite of GLP-1 mediates myocardial glucose uptake and improves left ventricular performance in conscious dogs with dilated cardiomyopathy. Am $\mathrm{J}$ Physiol Heart Circ Physiol 2005, 289(6):H2401-H2408.

14. Poornima I, Brown SB, Bhashyam S, Parikh P, Bolukoglu H, Shannon RP: Chronic glucagon-like peptide-1 infusion sustains left ventricular systolic function and prolongs survival in the spontaneously hypertensive, heart failure-prone rat. Circ Heart Fail 2008, 1(3):153-160.

15. Ravassa S, Zudaire A, Diez J: GLP-1 and cardioprotection: from bench to bedside. Cardiovasc Res 2012, 94(2):316-323.

16. Burkey BF, Li X, Bolognese L, et al: Acute and chronic effects of the incretin enhancer vildagliptin in insulin-resistant rats. J Pharmacol Exp Ther 2005, 315(2):688-695.

17. Lim S, Choi SH, Shin H, et al: Effect of a dipeptidyl peptidase-IV inhibitor, des-fluoro-sitagliptin, on neointimal formation after balloon injury in rats. PLoS One 2012, 7(4):e35007.

18. Hausenloy DJ, Maddock HL, Baxter GF, Yellon DM: Inhibiting mitochondrial permeability transition pore opening: a new paradigm for myocardial preconditioning? Cardiovasc Res 2002, 55(3):534-543.

19. Ye Y, Keyes KT, Zhang C, Perez-Polo JR, Lin Y, Birnbaum Y: The myocardial infarct size-limiting effect of sitagliptin is PKA-dependent, whereas the protective effect of pioglitazone is partially dependent on PKA. Am J Physiol Heart Circ Physiol 2010, 298(5):H1454-H1465.

20. Xiao YF, Nikolskaya A, Jaye DA, Sigg DC: Glucagon-like peptide-1 enhances cardiac L-type Ca2+ currents via activation of the CAMP-dependent protein kinase A pathway. Cardiovasc Diabetol 2011, 10:6.

21. Sauve M, Ban K, Momen MA, et al: Genetic deletion or pharmacological inhibition of dipeptidyl peptidase-4 improves cardiovascular outcomes after myocardial infarction in mice. Diabetes 2010, 59(4):1063-1073.

22. Yin M, Sillje HH, Meissner M, van Gilst WH, de Boer RA: Early and late effects of the DPP-4 inhibitor vildagliptin in a rat model of postmyocardial infarction heart failure. Cardiovasc Diabetol 2011, 10:85.

23. Zhao T, Parikh P, Bhashyam S, et al: Direct effects of glucagon-like peptide-1 on myocardial contractility and glucose uptake in normal and postischemic isolated rat hearts. J Pharmacol Exp Ther 2006, 317(3):1106-1113.

24. Zaruba MM, Theiss HD, Vallaster M, et al: Synergy between CD26/DPP-IV inhibition and G-CSF improves cardiac function after acute myocardial infarction. Cell Stem Cell 2009, 4(4):313-323.

25. Verspohl EJ: Novel therapeutics for type 2 diabetes: incretin hormone mimetics (glucagon-like peptide-1 receptor agonists) and dipeptidyl peptidase-4 inhibitors. Pharmacol Ther 2009, 124(1):113-138.

26. Cullinan CA, Brady EJ, Saperstein R, Leibowitz MD: Glucose-dependent alterations of intracellular free calcium by glucagon-like peptide- 1 (7-36amide) in individual ob/ob mouse beta-cells. Cell Calcium 1994 15(5):391-400

27. Hausenloy DJ, Yellon DM: New directions for protecting the heart against ischaemia-reperfusion injury: targeting the reperfusion injury salvage kinase (RISK)-pathway. Cardiovasc Res 2004, 61(3):448-460.

28. Hausenloy DJ, Yellon DM: Reperfusion injury salvage kinase signalling: taking a RISK for cardioprotection. Heart Fail Rev 2007, 12(3-4):217-234.

29. Chai W, Dong Z, Wang N, et al: Glucagon-like peptide 1 recruits microvasculature and increases glucose use in muscle via a nitric oxidedependent mechanism. Diabetes 2012, 61(4):888-896.

30. Noyan-Ashraf MH, Shikatani EA, Schuiki I, et al: A glucagon-like peptide-1 analog reverses the molecular pathology and cardiac dysfunction of a mouse model of obesity. Circulation 2013, 127(1):74-85.

31. Salt IP, Johnson G, Ashcroft SJ, Hardie DG: AMP-activated protein kinase is activated by low glucose in cell lines derived from pancreatic beta cells, and may regulate insulin release. Biochem J 1998, 335(Pt 3):533-539.

32. Lim A, Park SH, Sohn JW, et al: Glucose deprivation regulates KATP channel trafficking via AMP-activated protein kinase in pancreatic betacells. Diabetes 2009, 58(12):2813-2819.

33. Nikolaidis LA, Mankad S, Sokos GG, et al: Effects of glucagon-like peptide-1 in patients with acute myocardial infarction and left ventricular dysfunction after successful reperfusion. Circulation 2004, 109(8):962-965.

34. Sokos GG, Bolukoglu H, German J, et al: Effect of glucagon-like peptide-1 (GLP-1) on glycemic control and left ventricular function in patients undergoing coronary artery bypass grafting. Am J Cardiol 2007, 100(5):824-829.
35. Sokos GG, Nikolaidis LA, Mankad S, Elahi D, Shannon RP: Glucagon-like peptide-1 infusion improves left ventricular ejection fraction and functional status in patients with chronic heart failure. J Card Fail 2006, 12(9):694-699.

36. Noyan-Ashraf MH, Momen MA, Ban K, et al: GLP-1R agonist liraglutide activates cytoprotective pathways and improves outcomes after experimental myocardial infarction in mice. Diabetes 2009, 58(4):975-983.

37. Sonne DP, Engstrom T, Treiman M: Protective effects of GLP-1 analogues exendin-4 and GLP-1(9-36) amide against ischemia-reperfusion injury in rat heart. Regul Pept 2008, 146(1-3):243-249.

38. Timmers L, Henriques JP, de Kleijn DP, et al: Exenatide reduces infarct size and improves cardiac function in a porcine model of ischemia and reperfusion injury. J Am Coll Cardiol 2009, 53(6):501-510.

39. Read PA, Khan FZ, Heck PM, Hoole SP, Dutka DP: DPP-4 inhibition by sitagliptin improves the myocardial response to dobutamine stress and mitigates stunning in a pilot study of patients with coronary artery disease. Circ Cardiovasc Imaging 2010, 3(2):195-201.

40. Theiss HD, Brenner C, Engelmann MG, et al: Safety and efficacy of SITAgliptin plus GRanulocyte-colony-stimulating factor in patients suffering from acute myocardial infarction (SITAGRAMI-Trial)-rationale, design and first interim analysis. Int J Cardiol 2010, 145(2):282-284.

41. Lonborg J, Vejlstrup N, Kelbaek H, et al: Exenatide reduces reperfusion injury in patients with ST-segment elevation myocardial infarction. Eur Heart J 2012, 33(12):1491-1499.

doi:10.1186/1475-2840-12-154

Cite this article as: Hausenloy et al:: Dipeptidyl peptidase-4 inhibitors and GLP-1 reduce myocardial infarct size in a glucose-dependent manner. Cardiovascular Diabetology 2013 12:154.

\section{Submit your next manuscript to BioMed Central and take full advantage of:}

- Convenient online submission

- Thorough peer review

- No space constraints or color figure charges

- Immediate publication on acceptance

- Inclusion in PubMed, CAS, Scopus and Google Scholar

- Research which is freely available for redistribution 